\title{
Measurements in Standard Room Scale Fires
}

\author{
ANDREW LOCK, GWON HYUN KO, MATTHEW BUNDY, ERIK JOHNSSON, and ANTHONY \\ HAMINS \\ Fire Research Division, Building and Fire Research Laboratory \\ National Institute of Standards and Technology \\ 100 Bureau Drive \\ Gaithersburg, MD 20899
}

\begin{abstract}
In this paper the results of a continuing effort to develop a comprehensive compartment fire database for validation of numerical fire modeling is presented. Natural gas fires were conducted inside a full-scale ISO 9705 room and are compared with previous results obtained in a $2 / 5$ scale, reduced-scale enclosure. In these experiments, fires with heat release rates as large as $2.7 \mathrm{MW}$ were used in the full-scale room. Gas species and temperature measurements were made inside the room at several locations in the upper layer and the doorway. Oxygen, $\mathrm{CO} / \mathrm{CO}_{2}$, and total hydrocarbon gas analyzers were used in addition to gas chromatography to make gas species measurements. Temperature measurements were made in the upper layer of the room using aspirated thermocouples. Fires as large as $2.7 \mathrm{MW}$ were observed not to produce underventilated compartment fire conditions in the full-scale enclosure despite the large heat release rate and temperatures observed in excess of $1200^{\circ} \mathrm{C}$. A comparison of the gas species in the upper layer of the reduced-scale and full-scale results showed similarities in terms of the gas species volume fractions when plotted as a function of mixture fraction, but the temperature results showed that the full-scale enclosure was reaching higher temperatures than the reduced-scale enclosure.
\end{abstract}

KEYWORDS: iso 9705, compartment fire, enclosure fire, gas sampling, aspirated thermocouples, gas chromatography.

\section{INTRODUCTION}

The development of field models for the prediction of fire growth and smoke transport is an area of special interest to fire researchers, fire protection engineers, fire investigators, and those developing new fire safety technologies. Field models numerically solve the conservation equations of mass, momentum and energy that govern low-speed, thermally-driven flows with an emphasis on smoke and heat transport from fires. All fire field models have strengths and weaknesses. Past versions of FDS have used a mixture fraction based chemistry model which did not predict soot or intermediate combustion products such as CO. Instead $\mathrm{CO}$ and soot production was prescribed from literature data or bench scale experimental investigations [1]. The newest version of FDS (FDS v.5) includes a two part reaction model which allows for CO prediction [2]. Experiments, such as the compartment fires presented here, are designed to provide experimental data with well defined boundary conditions to facilitate further development of FDS by providing detailed gas species measurements including $\mathrm{CO}, \mathrm{H}_{2}$, and higher hydrocarbon species in addition to temperature data.

A primary goal of the experiments was to provide data on the realistic evolution of a fire as the heat release rate is increased until the fire reaches the underventilated or vitiated condition. Many previous experimental investigations have been conducted on the behavior of uncontrolled burning of fires in a confined space. The full-scale room as defined by the ISO 9705 [3] standard was used as a basis, because it is a large enclosure representative of a room in a residential structure and in order to be consistent with other investigations in full-scale room burning [4-6]. Relationships between reduced- and full-scale enclosure fire tests are used to develop scaling laws to relate the two. Reduced-scale tests are cheaper and easier to perform while full-scale tests provide a more realistic fire environment. Previous works have proposed scaling relationships in terms of temperature and ventilation with varying degrees of success $[5,7]$.

Pitts used the Global Equivalence Ratio (GER) concept, as developed by Zukoski and Beyler [8, 9], as a predictive method for the production of $\mathrm{CO}$ in enclosure fires [5]. This method considers the ratio of the total fuel consumption rate to the total air supply rate in the enclosure to calculate the global equivalence ratio and predict the quantity of $\mathrm{CO}$ and other species produced. It has been shown that this method works well to predict $\mathrm{CO}$ volume fraction in some fires and not in others. Specifically, lean fires are well predicted while most underventilated and extremely hot fires $\left(>900{ }^{\circ} \mathrm{C}\right)$ are not well predicted. Pitts' 
experiments considered only natural gas as a fuel. More recently Andersson [4] considered the GER applied to four more complicated fuels with similar findings: She also found that the GER generally works well only for relatively cool fires. The current investigation provides detailed species measurements in reduced-scale and full-scale enclosures to facilitate development and validation of field models.

The current predictive capability in FDS is based on the mixture fraction concept [2]. The mixture fraction relates the total mass of material originating in the fuel stream present at any given location. This concept was developed by Bilger to analyze flame data [10]. It was adapted to predict turbulent combustion in field models by Peters [11] and has been used to analyze the structure of laminar counterflow and coflow flames $[12,13]$. In FDS, the mixture fraction has been used to represent fire chemistry in terms of an irreversible instantaneous single chemical step, where fuel reacts completely with all available oxygen in a region to form complete combustion products. A new predictive scheme has been implemented in FDS 5 to predict the production of $\mathrm{CO}$ in underventilated fires, using two-step chemistry [2]. The results provided here were used as part of the model development.

Another issue surrounding the prediction of $\mathrm{CO}$ and other species is scalability. Scaling relationships allow a reduced or bench scale fire to be used as a basis for predicting the behavior of full-scale fires without the expense of creating a full-scale experiment. On this basis, many of the GER experiments as well as other enclosure experiments have been conducted in reduced-scale enclosures with the intent of using the results to predict full-scale fires. Pitts, Bryner, and others have used the $\mathrm{Ah}^{1 / 2}$ scaling factor, where $\mathrm{A}$ is area and $\mathrm{h}$ is height of an enclosure vent $[5,7,14]$. The $\mathrm{Ah}^{1 / 2}$ quantity is proportional to the area of the vent and the air flux into the enclosure [15-18]. Using this quantity the ventilation air flow into an enclosure is scaled as the square of the scaling factor. The $2 / 5$ scale ISO 9705 room used in this investigation will be referred to here as the reduced-scale enclosure (RSE). The RSE results are used for comparison with the full-scale results (FSE) and for an evaluation of previously developed scaling rules [19].

This paper summarizes the current progress on a long-term project experimentally characterizing the behavior of room fires. Natural gas fires are considered and experimental data on gas species, heat release rate and temperature are presented. The species composition results are compared to a mixture fraction model and with the results obtained previously in reduced-scale compartment fires. This experimental data is an improvement of previous data in the sense that it features well defined and steady wall boundary conditions and the gas species measurements are more detailed than previous measurements. It also provides further insight into the differences in dynamics between a reduced-scale and full-scale enclosure fire.

\section{EXPERIMENTAL CONFIGURATION}

The ISO 9705 standard stipulates a room with internal dimensions of $2.4 \mathrm{~m} \times 3.6 \mathrm{~m} \times 2.4 \mathrm{~m}$ with a door for ventilation that has dimensions of $2 \mathrm{~m} \times 0.8 \mathrm{~m}$ [3]. All dimensions in the room are allowed a tolerance of $\pm 4 \mathrm{~cm}$. The dimensions of the reduced-scale enclosure were $1.42 \mathrm{~m} \mathrm{x} 0.95 \mathrm{~m} \mathrm{x} 0.98 \mathrm{~m}$ with a doorway of $0.81 \mathrm{~m} \times 0.48 \mathrm{~m}$, or $2 / 5$ the scale of the full-scale room. The full-scale enclosure used in these experiments is shown in Fig. 1. The full-scale room was lined with a $2.5 \mathrm{~cm}$ thick noncombustible alumina-silicazirconia ceramic blanket. Investigations in the reduced-scale enclosure have shown that ceramic blanket was a stabile and reliable lining material for these experiments [19]. The structural stability and chemically non-reactive nature of the ceramic blanket also make it an easier boundary condition to prescribe for numerical modeling.

A water-cooled pool burner was placed in the center of the full-scale enclosure on the floor. The pool burner was a $1 \mathrm{~m}$ square pan with a total external height of $15 \mathrm{~cm}$. The internal surface of the burner was inclined. The reduced-scale enclosure (RSE) used a $13 \mathrm{~cm}$ square pan with a total height of $15 \mathrm{~cm}$ above the floor. House water flowed through the full-scale burner at a variable rate up to $57 \mathrm{~L} / \mathrm{min}$ to control the burner temperature. The RSE burner was not water cooled. The burners were filled with gravel and the house natural gas flow was metered to obtain the desired heat release rate. GC gas analysis of the house natural gas was conducted, as it differed slightly in each of the experiments.

Water-cooled gas sampling probes were inserted into the structure at points A and B, as illustrated in Fig. 1 . The locations of these points, relative to the origin indicated in Fig. 1, are listed in Table 1. These points are scaled geometrically between the measurement points in the reduced-scale and full-scale enclosures [19]. Temperature and soot measurement probes were also included at these locations in an attempt to capture a 


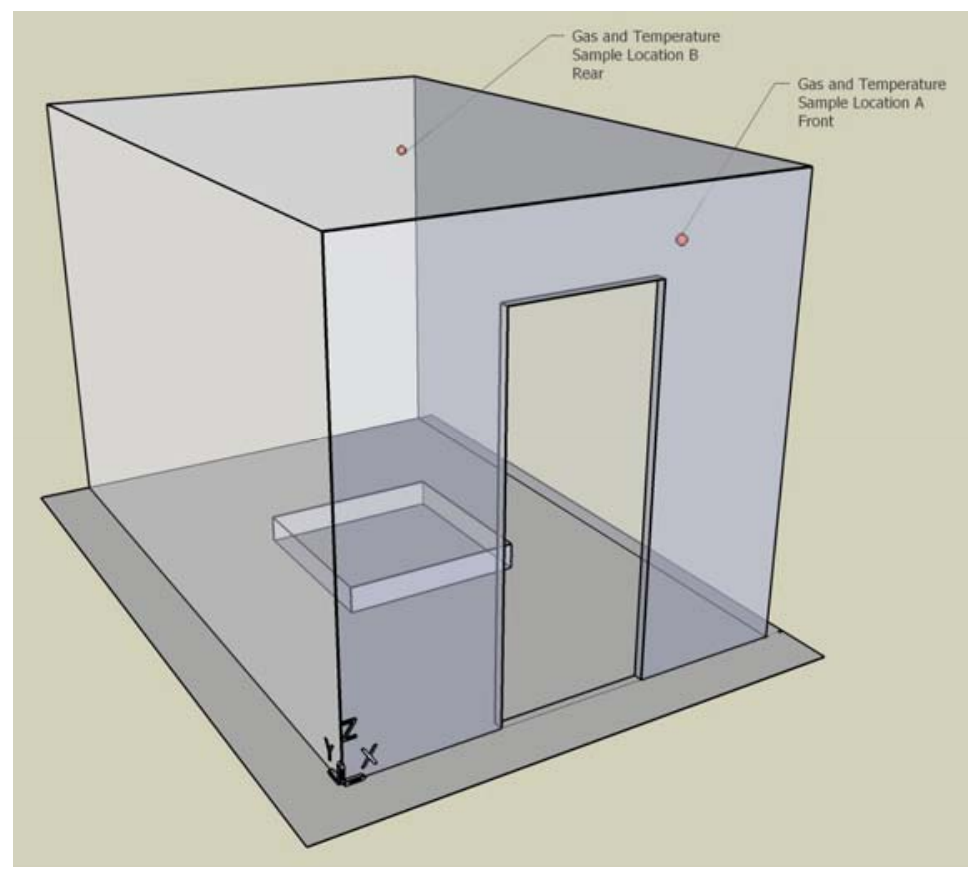

Fig. 1. Schematic drawing of the enclosure with internal sampling locations indicated. The sampling locations for the reduced- and full-scale enclosures are list in Table 1.

Table 1. Location of sampling points in the upper layer of the reduced-scale enclosure (RSE) and the fullscale enclosure (FSE).

\begin{tabular}{|c|c|c|c|c|c|c|c|}
\hline \multirow[t]{2}{*}{$\begin{array}{c}\text { Sample } \\
\text { Point }\end{array}$} & \multicolumn{2}{|c|}{$X(\mathbf{c m})$} & \multicolumn{2}{|c|}{$\mathbf{Y}(\mathbf{c m})$} & \multicolumn{2}{|c|}{$\mathrm{Z}(\mathbf{c m})$} & \multirow[t]{2}{*}{ Measurements } \\
\hline & RSE & FSE & RSE & FSE & RSE & FSE & \\
\hline A, Front & 29 & 189 & 10 & 25 & 88 & 208 & $\begin{array}{l}\text { Gas Species, } \\
\text { Temperature }\end{array}$ \\
\hline B, Rear & 29 & 189 & 113 & 286 & 88 & 208 & $\begin{array}{l}\text { Gas Species, } \\
\text { Temperature, }\end{array}$ \\
\hline
\end{tabular}

more complete picture of the fire environment. Temperature measurements were also made at various other locations inside the room [19].

Gas samples were pulled through two cooled $\left(\mathrm{T}=25^{\circ} \mathrm{C} \pm 5{ }^{\circ} \mathrm{C}\right)$ sample lines to freeze the chemistry. The sample then flowed to a heated line to prevent condensation and a Nafion polymer membrane, which selectively removed water from the gas stream [20]. The dried gas streams then flowed to a Servomex 4100 paramagnetic oxygen analyzer, a Siemens Ultramat $6 \mathrm{E}$ non-dispersive infrared (NDIR) $\mathrm{CO}$ and $\mathrm{CO}_{2}$ analyzer, a Baseline-Mocon $8800 \mathrm{H}$ total hydrocarbon analyzer using a flame ionization detector (FID), and finally to a Agilent 3000A micro gas chromatograph (micro-GC) for detailed gas analysis. The sample flow path was nearly identical to that reported for the RSE [19]. Each gas analyzer was calibrated before each test, the uncertainty introduced by the span and calibration gases was $1 \%$ [19]. The uncertainty in gas analyzer measurement through repeat experiments using a standard gas mixture [21]. A gas sampling and storage system was designed and constructed, allowing capture and storage of sixteen $10 \mathrm{ml}$ gas samples extracted from the front position in the room. The samples were stored for analysis after the experiment. The micro-GC was connected directly to the other gas sample line, sampling from the rear location, and continually sampled. Analysis of the gas flow was done every 2.5 minutes throughout each test. The uncertainty in GC measurement was less than $1 \%$ based on calibration and the repeatability tests. All of the exhaust gasses from the room fires were captured by the $6 \mathrm{~m}$ hood at the NIST Large Fire Laboratory 
(LFL), where oxygen-consumption calorimetry was conducted to determine the fire heat release rate [22, 23]. The LFL $6 \mathrm{~m}$ hood calorimetry has been shown to have a combined expanded uncertainty of $14 \%$. The expanded uncertainty refers to a factor of two times the standard uncertainty.

Aspirated thermocouples were used for internal room temperature measurements. These thermocouples work by pulling combustion gasses directly from a sample location at a high velocity over a thermocouple bead enclosed by two radiation shields [24]. The aspirated thermocouples sacrifice temporal and spatial resolution, but lead to significantly reduced radiative exchange, as compared to bare bead thermocouples, and generally improve measurement accuracy. The expanded uncertainty in the temperature measurements taken in the upper layer was estimated as $7 \%$ [24].

\section{RESULTS AND DISCUSSION}

Experiments were conducted for a variety of fire sizes with natural gas as the fuel in both the reduced and full-scale enclosures. Figure 2 shows a photographic image of a natural gas fire at $2.7 \mathrm{MW}$ in the full-scale enclosure with flames emanating from the front of the enclosure. Despite this behavior, indicative of underventilated burning, a completely vitiated environment was not measured in the upper layer of the room, as will be discussed later. Figure 3 presents experimental data collected from several fires, combined together and organized by the size of the enclosure, i.e. reduced-scale and full-scale. Each test started at a low heat release rate (HRR), which was gradually increased in steps to a maximum heat release rate of 2.7 MW for the full-scale and $400 \mathrm{~kW}$ for the reduced-scale fires. Each step in the HRR was allowed to stabilize, so that the measurements were acquired for near-steady fire sizes. Nominal fire sizes were $0.9 \mathrm{MW}, 1.25 \mathrm{MW}, 2.4 \mathrm{MW}$, and 2.7 MW in the full-scale enclosure experiments and $0.15 \mathrm{MW}, 0.2 \mathrm{MW}$, $0.25 \mathrm{MW}$, and $0.4 \mathrm{MW}$ in the reduced-scale enclosure experiments.

Quantitative differences between the gas analyzer results and the GC gas sample analysis were generally less than $1 \%$ in both reduced and full-scale

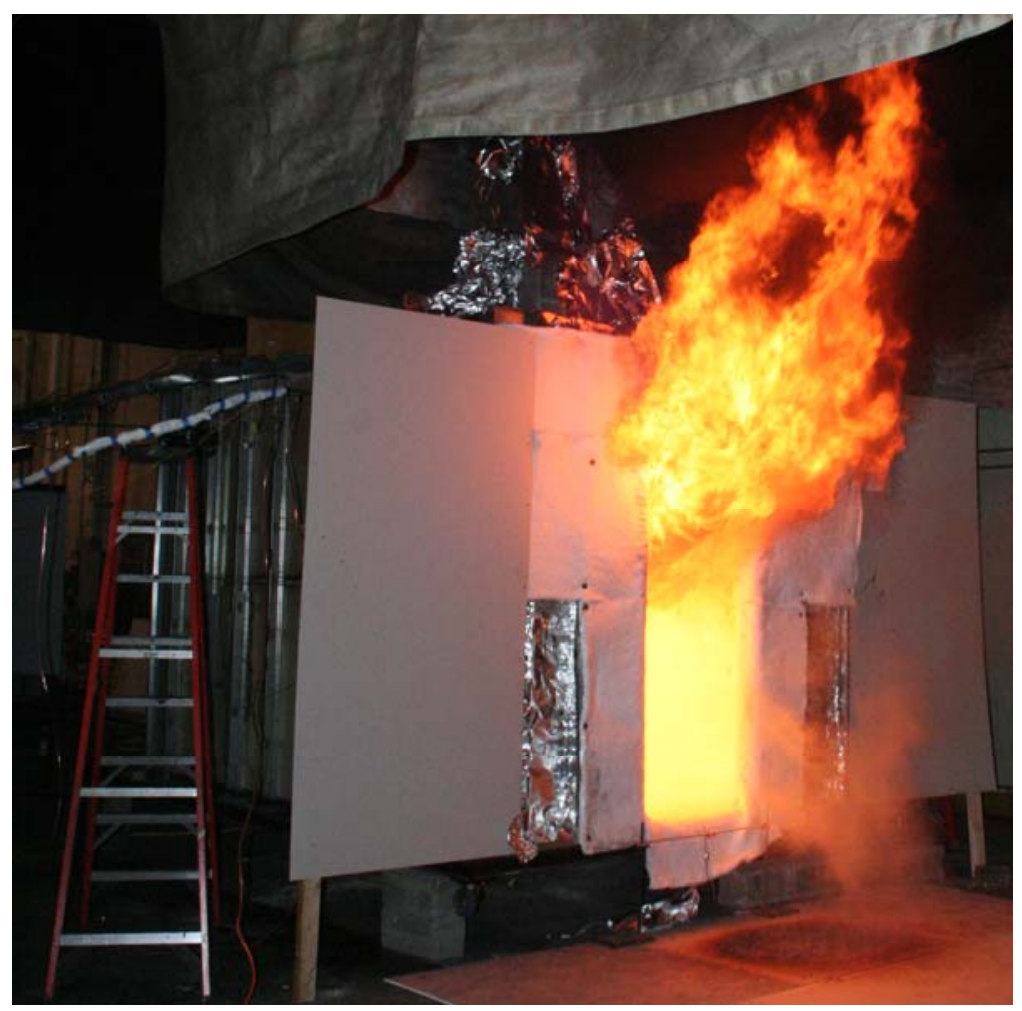

Fig. 2. Image of a $2.7 \mathrm{MW}$ natural gas fire in the full-scale enclosure. 
Figure 3 shows the measured volume fraction of gas species at Position A (left) and Position B (right) in the upper layer of natural gas fires burning in the reduced-scale enclosure, RSE, (top) and the full-scale enclosure, FSE (bottom) as a function of the heat release rate. Each data point in Fig. 3 was averaged over the steady burning period in the experiment to statistically determine standard deviation in the measurements. These plots indicate several trends. The variation in the gas species concentrations qualitatively follows the expected behavior relative to the heat release rate. That is, as the heat release rate increased, oxygen in the room was consumed and more product species such as $\mathrm{CO}_{2}$ and intermediate species, such as $\mathrm{CO}$ were present. Steady state was reached within 2 min after a step change in the fuel delivery rate. Soot volume fraction was measured and found to be relatively insignificant for the natural gas fires (less than $0.1 \%$, and often unmeasureable).

Intermediate species were not observed in appreciable quantities until the HRR reached $2.7 \mathrm{MW}$ in the fullscale fire and $250 \mathrm{~kW}$ in the reduced-scale enclosure. According to the simple $\mathrm{Ah}^{1 / 2}$ scaling relationship, if intermediate species were observed at $250 \mathrm{~kW}$ in the reduced-scale enclosure, then one could expect them

Front, Position A
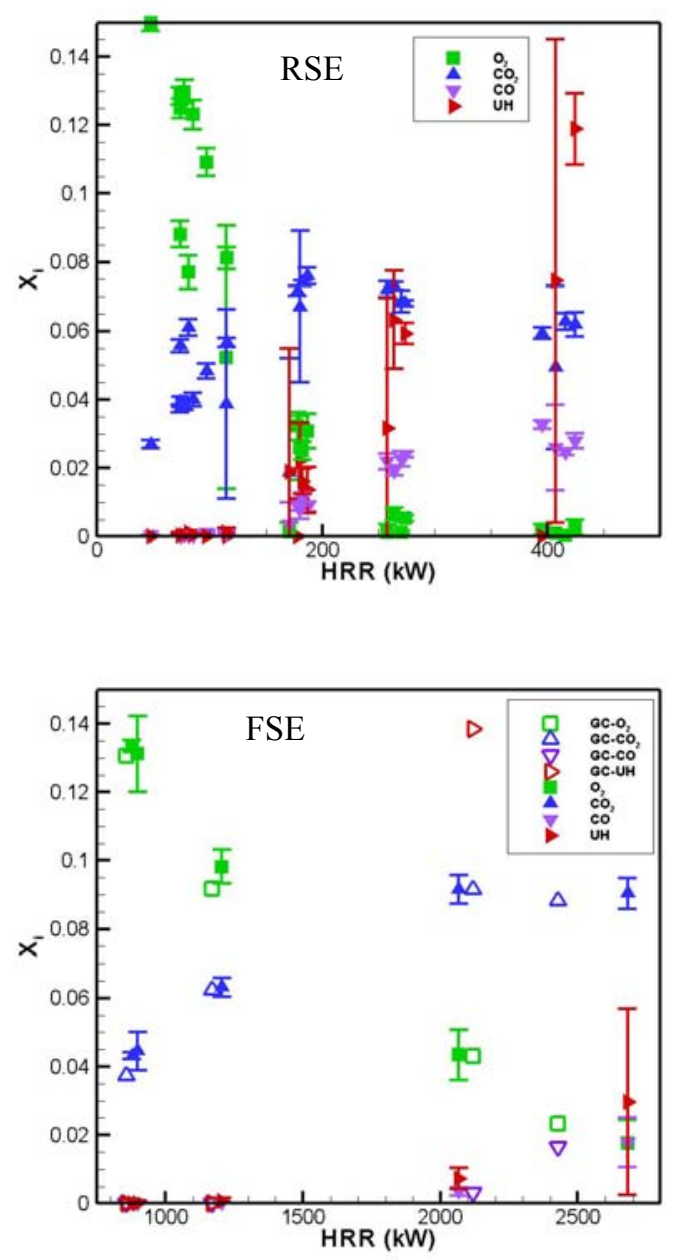

Rear, Position B
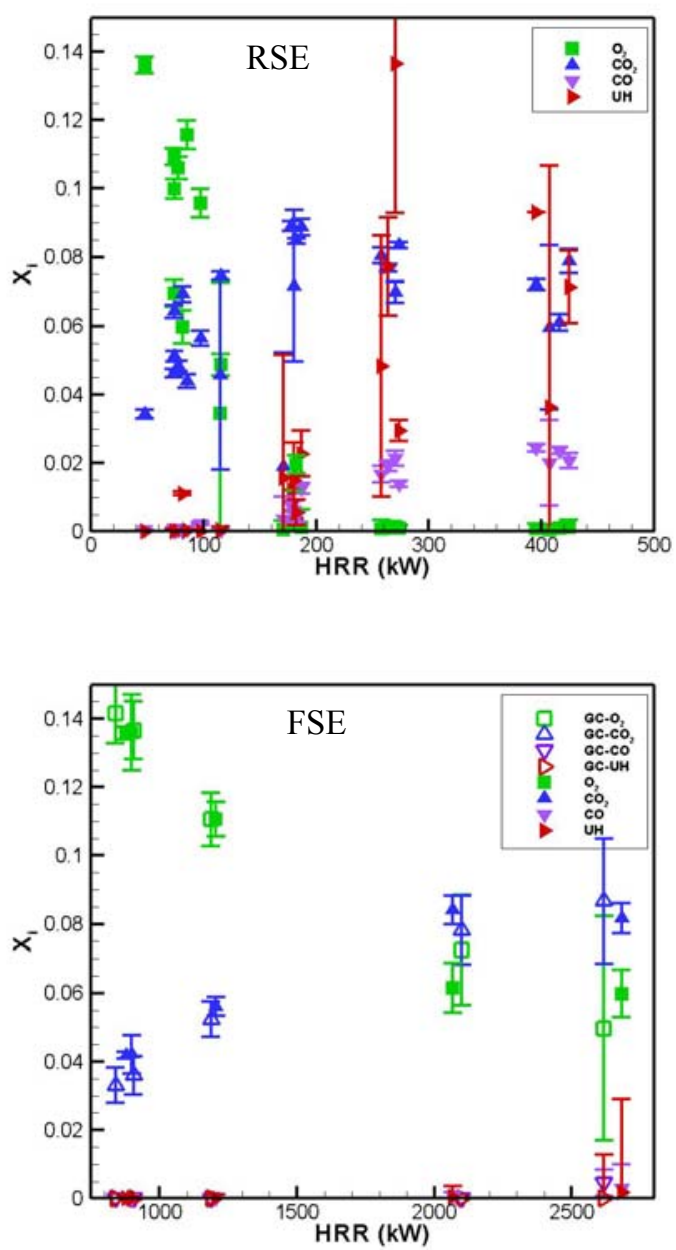

Fig. 3. Measured gas volume fractions at Position A (left) and Position B (right) in the upper layer of natural gas fires burning in the reduced-scale enclosure, RSE, (top) and the full-scale enclosure, FSE

(bottom) as a function of the heat release rate. 
to be present 1.6 MW in the full-scale enclosure. This indicates that in a global sense that the full-scale enclosure was burning slightly lean and that underventilated conditions (no oxygen present), and thereby enclosure chemistry, did not occur as predicted by the scaling relationship. Different dynamics also seem to come into play for these two enclosures. In the reduced-scale enclosure, both front and rear sampling locations had approximately the same levels of $\mathrm{CO}$ and unburnt hydrocarbons. This was not true for the full-scale fires, indicating that the upper layer of the room was more homogeneous in the reduced-scale than in the full-scale enclosure. In the full-scale enclosure, at the peak heat release rate, less oxygen and more $\mathrm{CO}$ and unburnt hydrocarbons (UHC) were observed at point $\mathrm{A}$, near the front of the enclosure, while slightly more oxygen and less $\mathrm{CO}$ or $\mathrm{UHC}$ were observed at point $\mathrm{B}$, in the rear of the enclosure. This indicates that as air enters the room, it is transported quickly to the rear of the compartment and was only vitiated as it approached the front of the enclosure, just prior to exiting.

\section{Mixture Fraction Analysis}

The mixture fraction is defined as the local mass fraction of species which originated in the fuel stream:

$$
Z=Y_{F}+Y_{c o} \frac{M W_{F}}{x M W_{c o}}+Y_{c o_{2}} \frac{M W_{F}}{x M W_{c o_{2}}}+Y_{\text {Soot }} \frac{M W_{F}}{x M W_{\text {Soot }}}
$$

Where $\mathrm{Z}$ is the local mixture fraction, $\mathrm{Y}_{\mathrm{F}}, \mathrm{Y}_{\mathrm{CO}}, \mathrm{Y}_{\mathrm{CO} 2}$, and $\mathrm{Y}_{\text {Soot }}$ represent the mass fractions of Fuel, $\mathrm{CO}$, $\mathrm{CO}_{2}$, and Soot respectively. $\mathrm{x}$ is the number of carbon atoms in the fuel, $\mathrm{MW}_{\mathrm{F}}, \mathrm{MW}_{\mathrm{CO}}, \mathrm{MW}_{\mathrm{CO} 2}$, and $\mathrm{MW}_{\text {Soot, }}$ are the molecular weights of Fuel, $\mathrm{CO}, \mathrm{CO}_{2}$, and Soot. Local mass fractions of key species are plotted versus mixture fraction and presented for natural gas fires in Fig. 4. The stoichiometric mixture fraction, $Z_{\mathrm{st}}$, is the mixture fraction at which the stoichiometric ratio of fuel to air is present. For natural gas the stoichiometric mixture fraction was approximately $Z_{\mathrm{st}}=0.0554 \pm 0.0002$ [19]. The uncertainty in this number is related to the uncertainty in the GC gas analysis of the house natural gas, which differed slightly in each of these experiments. At larger mixture fractions, theory predicts that all oxygen consumed and incomplete combustion products are formed. At smaller mixture fractions all of the fuel is consumed producing only complete combustion products. This theory works well at predicting local chemical compositions for lean fires, however it has been well documented that for $Z>Z_{\mathrm{st}}$, the measured composition deviates significantly from the theoretically predicted composition [19].

The local species mass fractions are plotted as a function of the mixture fraction in Fig. 4. For both the reduced and full-scale fires, the previous comments about mixture fraction hold true in that the measured local chemical composition follows the theoretical state relationship trends well for $Z<Z_{\text {st }}$ and then deviates after $Z>Z_{\text {st. }}$. In reduced-scale, an underventilated condition was achieved readily and the mixture fraction increased to a level in which a significant amount of $\mathrm{CO}$ was present and oxygen was completely consumed. For these rich conditions, as expected the $\mathrm{CO}$ mass fraction did not follow the state relationships, as was also true for the mass fractions $\mathrm{H}_{2} \mathrm{O}$ and $\mathrm{CO}_{2}$, which were both underpredicted. For the full-scale enclosure, even though the volume fraction of oxygen did not drop to zero, the local chemical system does transition to a slightly rich-burning regime, $Z>Z_{\text {st }}$, where more partial combustion products are produced. Specifically, there was an increase in total hydrocarbons, mostly methane, and an increase in $\mathrm{CO}$, which was not predicted by the state relationships, which assumes complete combustion. Strong agreement was still observed between the experimentally measured gas species concentrations and the theoretically predicted composition of the gas for $Z<Z_{\text {st }}$. The disparity in the scaling relationship is also evident from Fig. 4. Even though the heat release rate in the full-scale enclosure reached a level of 2.7 MW, well in excess of the predicted underventilated condition based on the reduced-scale enclosure, the chemistry in the upper layer was only beginning to produce substantial products of incomplete combustion. 


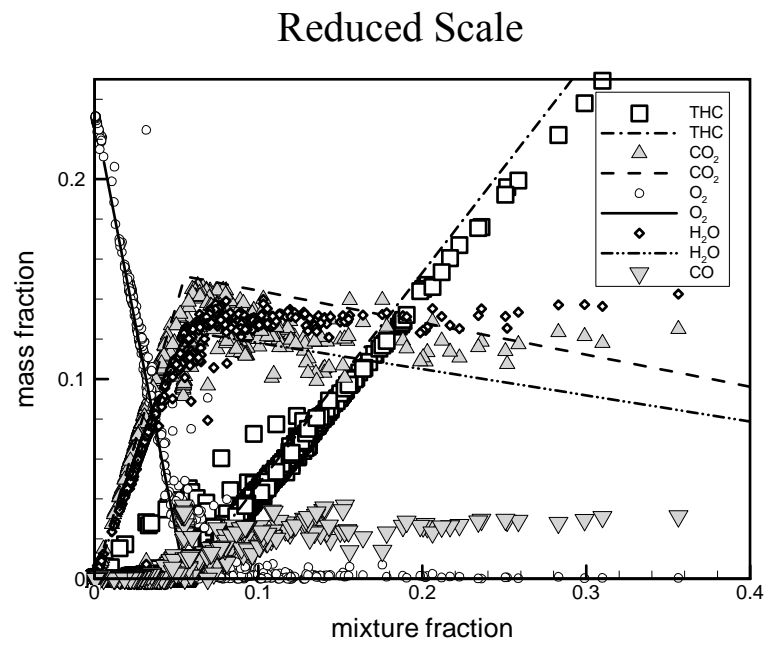

Full Scale

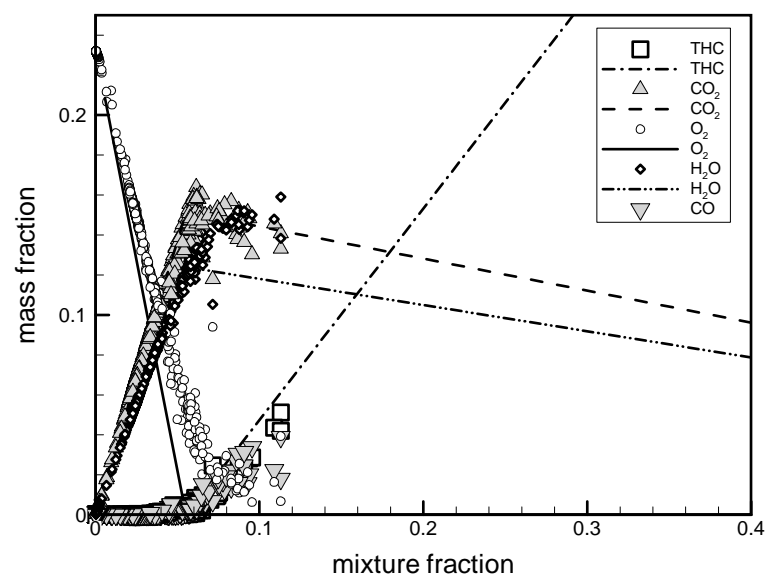

Fig. 4. Measured mass fractions (symbols) and theoretical mass fractions (lines) of important reactant, product, and intermediate species plotted as a function of mixture fraction in the upper layer of a reducedscale enclosure (left) and full-scale enclosure (right) burning natural gas.

The temperatures inside the reduced-scale and full-scale enclosures are presented in Fig. 5 as a function of local mixture fraction. In the reduced-scale enclosure there was a significant difference in the measured gas temperatures, approximately $300{ }^{\circ} \mathrm{C}$, in spite of the fact that the local mixture fractions are largely similar. In the full-scale enclosure, the opposite was observed in that very similar temperatures are observed despite the fact that a larger mixture fraction was observed in the front of the enclosure than in the rear. Specifically, for the full-scale at the rear of the enclosure, the high level of oxygen (as indicated by $Z<Z_{\text {st }}$ and observed in Fig. 3) was unexpected since the sampling location was remote from the doorway vent. Despite the locally similar temperatures between the front and rear of the enclosure, the ventilation profile was such that as fresh air enters the front of the enclosure it flows along the floor and rises in the rear of the enclosure. This indicates that there are different flow dynamics occurring in the full-scale enclosure than were observed in the reduced-scale enclosure. Different enclosure dynamics are credited with the reason that the scaling relationships are under-predicting the heat release rate necessary to achieve the underventilated condition. 
Reduced Scale

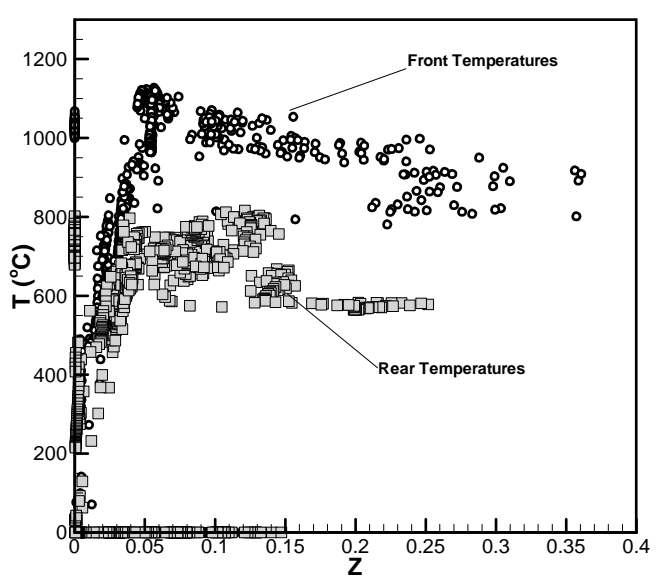

Full Scale

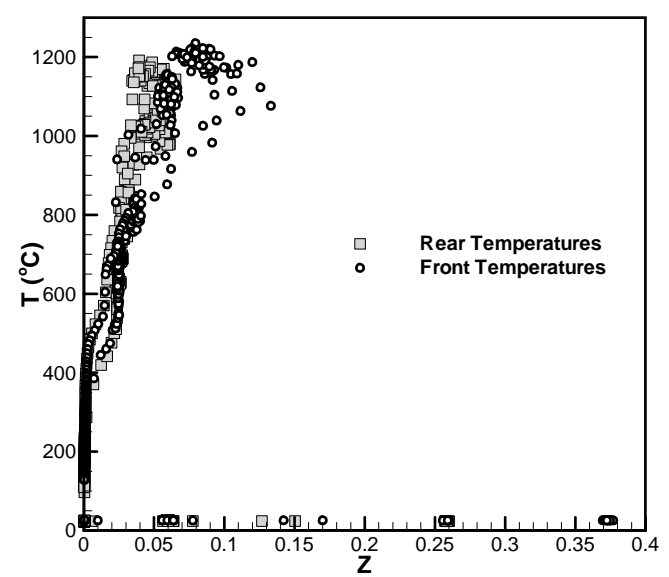

Fig. 5. Aspirated thermocouple temperatures in the upper layer of natural gas fires burning in the reducedscale enclosure (left) and the full-scale enclosure (right) as a function of the local mixture fraction, $\mathrm{Z}$.

The other salient feature of Fig. 5 is that the temperatures observed in the full-scale enclosure are higher than those observed in the reduced-scale enclosure. This is significant because it may contribute to the explanation of the failure of the simple scaling relationship. In the reduced-scale enclosure, underventilated fires were easily achieved for natural gas with a HRR of $250 \mathrm{~kW}$ [19]. The full-scale ISO room was just becoming underventilated at $2.7 \mathrm{MW}$, cf. Fig. 3. According to the ventilation scaling mentioned earlier [5, 7] the full-scale ISO room should be expected to be underventilated at 1.6 MW. The GER concept on

which the ventilation scaling was based has been shown to be valid for certain ventilation conditions and generally for temperatures less than $900{ }^{\circ} \mathrm{C}[4,5]$. As seen in Fig. 5, the temperature in the full-scale room was often above this threshold, with temperatures observed in excess of $1200{ }^{\circ} \mathrm{C}$. In a previous report by Pitts et al. [25], results for reduced and full-scale enclosures showed better agreement with this scaling rule, but for a different burner configuration, again suggesting different enclosure dynamics play a significant role in how incomplete combustion products are being produced.

\section{SUMMARY}

Full-scale room fire tests were conducted in an ISO 9705 standard room and a 2/5 scaled room. Gas species and temperatures were compared with the reduced-scale enclosure fire tests. Heat release rates up to 2.7 MW were produced in the full-scale enclosure. Instrumentation included oxygen-loss calorimetry for heat release rate measurements, aspirated thermocouples for temperature measurements, and several gas analyzers for gas species measurements. The main findings are:

1. In the full-scale enclosure, oxygen levels were only observed to drop to near zero levels occasionally in these experiments. None of the heat release rates tested produced a steady underventilated fire. This was also seen in the very low levels of intermediate products and unburnt fuel. This is in contrast to the reduced-scale fires which were more easily underventilated. This indicates that simple scaling laws may be inappropriate. Scaling of the burner area may also play a role.

2. Mixture fraction calculations based on fuel, $\mathrm{CO}$, and $\mathrm{CO}_{2}$ mass fractions measured in the fire showed that for lean fires $\left(Z<Z_{s t}\right)$ the mixture fraction does a reasonable job of predicting the composition. For $\mathrm{Z}>\mathrm{Z}_{\mathrm{st}}$ the experimental measurements departed from the theoretical predictions significantly. This is in line with previous observations. The behavior of the reduced-scale enclosure mimicked the full-scale. 
3. The full-scale enclosure was only observed to approach an underventilated condition at $2.4 \mathrm{MW}$. Reduced-scale enclosure fires became underventilated at $250 \mathrm{~kW}$, this suggested that the full-scale enclosure would become underventilated at $1.6 \mathrm{MW}$. This difference in required heat release rate is not consistent with the ventilation scaled prediction for the $2 / 5$ scale reduced-scale enclosure.

4. The deviation in measured results from that predicted by the scaling relationship is attributed to two factors. First, even though the room geometry was scaled geometrically, the burner geometry was not. This produced a different dynamic flow behavior in the room which may have affected the scaling. Second, the temperatures in the reduced-scale enclosure were near $1000{ }^{\circ} \mathrm{C}$ while temperatures in the full-scale enclosure were in excess of $1200{ }^{\circ} \mathrm{C}$. Previous authors have shown that the scaling relationship fails at predicting ventilation conditions when the enclosure temperature is in excess of $900{ }^{\circ} \mathrm{C}$.

\section{ACKNOWLEDGEMENTS}

A number of individuals were instrumental in the completion of this work. The fabrication work and execution of these tests would not be possible without the expert assistance of the LFL staff: Alex Maranghides, Laurean DeLauter, Edward Hnetovsky, Greg Masenheimer, Jay McElroy, and Tony Chakalis.

\section{DISCLAIMER}

Certain companies and commercial properties are identified in this paper in order to specify adequately the source of information or of equipment used. Such identification does not imply endorsement or recommendation by the National Institute of Standards and Technology, nor does it imply that this source or equipment is the best available for the purpose.

\section{REFERENCES}

[1] National Fire Protection, A.; Society of Fire Protection, E., SFPE handbook of fire protection engineering. National Fire Protection Association, Quincy, Mass, 2002.

[2] McGrattan, K. B.; Baum, H.; Rehm, R.; Hostikka, S.; Floyd, J. "Fire Dynamics Simulator (Version 5): Technical Reference Guide;" National Institute of Standards and Technology, NIST SP 1018-5: 2007.

[3] ISO9705 "Fire Tests - Full-Scale Room Test for Surface Products First Edition;" International Ogranization for Standardization: Geneva, Switzerland, 1993.

[4] Andersson, B.; Markert, F.; Holmstedt, G., (2005) Combustion products generated by heteroorganic fuels on four different fire test scales, Fire Safety Journal 40, (5): 439-465. http://dx.doi.org/10.1016/j.firesaf.2005.03.002

[5] Pitts, W. M., (1995) The Global Equivalence Ratio Concept and the Formation Mechanisms of Carbon-Monoxide in Enclosure Fires, Progress in Energy and Combustion Science 21, (3): 197237.

[6] Pitts, W. M.; Johnsson, E. L.; Bryner, N. P., (1994) Carbon Monoxide Formation in Fires By High-Temperature Anaerobic Wood Pyrolysis, Twenty-Fifth Symposium (International) on Combustion: 1445-1462.

[7] Bryner, N. P.; Johnson, E. L.; Pitts, W. M. "Carbon Monoxide Production in Compartment Fires Reduced-Scale Enclosure Test Facility;" National Institute of Standards and Technology, NIST IR 5568: 1994.

[8] Beyler, C. L., (1986) Major Species Production by Diffusion Flames in A 2-Layer Compartment Fire Environment, Fire Safety Journal 10, (1): 47-56. http://dx.doi.org/10.1016/0379-

$\underline{7112(86) 90031-7}$ 
[9] Zukoski, E. E.; Morehart, J. H.; Kubota, T.; Toner, S. J., (1991) Species Production and Heat Release Rates in 2-Layered Natural-Gas Fires, Combustion and Flame 83, (3-4): 325-332. http://dx.doi.org/10.1016/0010-2180(91)90079-Q

[10] Bilger, R. W., (1977) Reaction-Rates in Diffusion Flames, Combustion and Flame 30, (3): 277284. http://dx.doi.org/10.1016/0010-2180(77)90076-1

[11] Peters, N., (1984) Laminar Diffusion Flamelet Models in Non-Premixed Turbulent Combustion, Progress in Energy and Combustion Science 10, (3): 319-339. http://dx.doi.org/10.1016/0360$\underline{1285(84) 90114-X}$

[12] Hamins, A.; Seshadri, K., (1987) The Structure of Diffusion Flames Burning Pure, Binary, and Ternary Solutions of Methanol, Hepatane, and Toluene, Combustion and Flame 68, (3): 295-307. doi:10.1016/0010-2180(87)90006-X

[13] Sivathanu, Y. R.; Faeth, G. M., (1990) Generalized State Relationships for Scalar Properties in Nonpremixed Hydrocarbon Air Flames, Combustion and Flame 82, (2): 211-230. http://dx.doi.org/10.1016/0010-2180(90)90099-D

[14] Hull, T. R.; Carman, J. M.; Purser, D. A., (2000) Prediction of CO evolution from small-scale polymer fires, Polymer International 49, (10): 1259-1265. http://dx.doi.org/10.1002/10970126(200010)49:10\%3C1259::AID-PI573\%3E3.0.CO;2-D

[15] Gross, D.; Roberston, A. F. "Experimental fires in enclosures", Tenth International Symposium on Combustion, 1965; 1965; pp 931-942.

[16] Heskestad, G. "Modeling of enclosure fires", Fourteenth International Combustion Symposium, 1972; 1972; pp 1021-1030.

[17] Kawagoe, K. "Fire behavior in rooms;" Building Research Institute of Japan, 27: September, 1958.

[18] Quintiere, J. G., (1989) Scaling Applications in Fire Research, Fire Safety Journal 15, (1): 3-29. http://dx.doi.org/10.1016/0379-7112(89)90045-3

[19] Bundy, M.; Hamins, A.; Johnsson, E. L.; Kim, S. C.; Ko, G. H.; Lenhert, D. B. "Measurements of Heat and Combustion Products in Reduced-Scale Ventilation-Limited Compartment Fires;" National Institute of Standrads and Technology, TN1483: 2007.

[20] Mauritz, K. A.; Moore, R. B., (2004) State of understanding of Nafion, Chemical Reviews 104, (10): 4535-4585. http://dx.doi.org/10.1021/cr0207123

[21] Taylor, B. N.; Kuyatt, C. E. "Guidelines for Evaluating and Expressing the Uncertainty of NIST Measurement Results;" National Institute of Standards and Technology, NIST TN 1297: Gaithersburg, MD, 1994.

[22] Brohez, S., (2005) Uncertainty analysis of heat release rate measurement from oxygen consumption calorimetry, Fire and Materials 29, (6): 383-394. http://dx.doi.org/10.1002/fam.895

[23] Bryant, R. A.; Ohlemiller, T. J.; Johnsson, E. L.; Hamins, A.; Grove, B. S.; Maranghides, A.; Mulholland, G. W.; Guthrie, W. F. "The NIST 3 Megawatt Quantitative Heat Release Rate Facility - Description and Proceedure;" NIST IR 7052: 2004.

[24] Blevins, L. G.; Pitts, W. M., (1999) Modeling of bare and aspirated thermocouples in compartment fires, Fire Safety Journal 33, (4): 239-259. http://dx.doi.org/10.1016/S0379$\underline{7112(99) 00034-X}$

[25] Pitts, W. M.; Bryner, N. P.; Johnson, E. L. "Combustion Product Formation in Under and Overventilated Full-Scale Enclosure Fires", Combustion Institute/Central and Western States (USA) and Combustion Institute/Mexican National Section and American Flame Research Committee. Combustion Fundamentals and Applications. Joint Technical Meeting, San Antonio, TX, 1995; J. P. Gore, (Ed.) San Antonio, TX, 1995; pp 565-570 http://dx.doi.org/10.1016/0360$\underline{1285(95) 00004-2}$ 